\title{
How Student Recruitment and Selection Can Impact Reentry Outcomes: Lessons from the Michigan Department of Corrections and Jackson College
}

\author{
by TERRELL A. BLOUNT \\ Vera Institute of Justice \\ TODD BUTLER \\ Jackson College \\ HEATHER GAY \\ Michigan Department of Corrections
}

\begin{abstract}
In 2013, the Vera Institute of Justice launched the Unlocking Potential: Pathways from Prison to Postsecondary Education Project (Pathways), a five-year multi-state demonstration project. Pathways aimed to increase educational attainment and employment opportunities for incarcerated and formerly incarcerated individuals by supporting an expansion of educational opportunities in prison. Corrections departments in the states of New Jersey, Michigan, and North Carolina were selected to participate in the initiative. Each college-in-prison program — although executed differently and offering varying programs of study — possessed one common theme: to equip incarcerated persons with the tools necessary to end the cycle of incarceration through high-quality postsecondary education. This paper examines approaches to student recruitment taken by the Michigan site during its implementation phase and suggests potential outcomes for college-in-prison programs to consider when using the "return communities" approach.
\end{abstract}

Keywords: Prison education; postsecondary correctional education; college in prison

Over the last several decades, the United States experienced a sharp decline in the number of colleges providing classroom-based instruction to the incarcerated population. With the support of Pell grants, college education in prisons flourished from the 1970s to the 1990s (Adams, 1973). In 1994 however, nearly all programs were discontinued when Congress moved to ban people incarcerated in state and federal facilities from receiving federal aid to cover their costs of tuition (Fine, 2001). At its peak use in prisons immediately preceding the ban, prisoners accounted for less than $1 \%$ of all Pell grant recipients: there was 1 imprisoned Pell student for every 499 students receiving Pell grants in the community (Morra, 1994). State aid programs soon followed suit (Fine, 2001), leaving what few programs remained heavily dependent on private funding or volunteer initiatives (often non-credit bearing), and forced to drastically reduce the number of students in their prison classrooms. Other programs offered distance learning through correspondence courses in liberal arts or theological studies, but were forced to limit enrollment to students who could pay for the courses themselves.

Prison populations massively increased in the 1990s and into the early 2000s, capping off in 2009 with 1.5 million people behind bars (National Research Council, 2014). That figure holds steady today (Carson and Anderson, 2016), driven in part by the high rate at which people return to prison within three years: 55 percent (Durose, 2014). Given these trends, postsecondary correctional education reemerged as an interest to many policy makers, researchers, and philanthropic organizations in the mid-2000s. Research demonstrated that postsecondary education could reduce recidivism and improve other post-release outcomes such as civic 
participation, employment and income, and intergenerational prosperity (Delaney et al, 2016).

In 2012, the Vera Institute of Justice launched the Unlocking Potential: Pathways from Prison to Postsecondary Education Project (Pathways), a five-year multi-state demonstration project. Pathways aimed to increase educational attainment and employment opportunities for incarcerated and formerly incarcerated individuals by supporting an expansion of college opportunities in prison. The initiative, funded by five leading foundations, ${ }^{1}$ involved sixteen prisons and fifteen colleges and universities throughout three selected states: New Jersey, Michigan, and North Carolina. Each college-in-prison program - although executed differently and offering varying programs of study_ possessed one common theme: equipping incarcerated persons with the tools necessary to end the cycle of incarceration through high-quality postsecondary education. Throughout the project, the colleges and corrections agencies developed innovative approaches to a number of implementation challenges. This article - which draws on the experience of the Michigan Pathways projectexplores student recruitment and selection, and the potential outcomes for college-prison programs serving students returning to specific areas post-release.

\section{Program Overview}

For the Pathways project, the Michigan Department of Corrections (MDOC) partnered with Jackson College (JC), a two-year college located in Jackson County, Michigan. JC served students in Macomb Correctional Facility, a men's mixed-security prison, and Parnall Correctional Facility, a men's minimum security prison. Michigan implemented a "2 years in, 2 years out" model, providing students with two years of classroom instruction and program support while incarcerated, followed by two years of continued educational and reentry support after release. Eligible students were required to return to one of the two cities in Michigan selected as designated return communities where project partners developed bridge services to re-connect students with college after they left prison. These aspects of the program design distinguished Michigan Pathways from many other college programs in prison, which typically do not offer support for their students during the reentry phase.

Under the partnership agreement with MDOC, JC offered courses to eligible students, who, upon completion of the program, would receive a Michigan General Transfer Certificate (GTC). Generally, the GTC recognizes the completion of general education requirements and awards recipients thirty credits (for those courses completed) toward an Associate's degree at any Michigan state university or community college. While the original intention of the GTC was to enable students in the community to easily transfer from one college to another to pursue the major of their choosing, the GTC was especially beneficial for Pathways students because 1) it required a shorter amount of time to complete than an AA or BA degree while in prison, 2) it equipped students with the general requirements needed to pursue most AA/BA degrees, and 3) it did not restrict students to a single major or concentration, allowing them to pursue their preferred major once released.

\section{Recruiting Eligible Students from the Prison Population}

Similar to the process of accepting applicants into a college or university in the community, student selection for a college-in-prison program should also reflect standards that ensure eligible and qualified candidates are treated with fairness and equity. Postsecondary institutions teaching in prisons need to be thoughtful about the benefits and disadvantages of various student selection approaches, including: "first-come firstserved," randomly generated lists, or selection based on sentence length or age of student. For instance, selecting all incarcerated people in a given facility with high school credentials and performing a randomized list of new enrollments may seem like a just approach, but prison release dates vary individually and can result in departures mid-semester, interrupting a student's education. A "first-come first-served" approach has its obvious flaws in the simple fact that prospective students living in housing units that are called last—whether randomly or strategically selected-will likely be unable to participate, especially if the number of enrollment slots are scarce. Commissary, religious services, and other correctional programming held during the time of registration may also prohibit the movement of people incarcerated within the facility.

The five foundations included the Ford Foundation, the Sunshine Lady Foundation, the Open Society Foundations, the W.K. Kellogg Foundation, and the Bill \& Melinda Gates Foundation. Since its launch, the project has also received support from the Laughing Gull Foundation. 
Where colleges in the community tend to have a generous pool of qualified applicants, colleges operating in prisons have a narrower group to choose from with approximately $30 \%$ of the US prison population having below high school education (Rampey et al, 2016). Additional factors narrow applicant pools even more, including incarcerated people who qualify but are uninterested in enrolling, are too close to their release date (and therefore cannot complete a semester), or have other reasons preventing participation. ${ }^{2}$ In 2012 , MDOC had a prison population slightly over 43,300 people. Of this population, $69 \%$ had achieved a high school diploma (HSD) or received high school equivalency by passing the test for General Education Development (GED), and 11,200 were either actively participating in an educational program or on waiting lists. Approximately $22 \%$ of those who achieved a HSD/GED had taken some postsecondary academic courses, but none had completed a degree. Students in Michigan Pathways were required to have achieved a HSD or GED, scored at least at the 9th grade level in Math and Reading on the Test for Adult Basic Education (TABE), and have a release date within two to three years of the Pathways program implementation date.

To ensure this opportunity was not exclusive to the population in the two designated Pathways facilities, MDOC recruited students statewide. MDOC's Education Director-who provides oversight for planning and performance of educational programming for the state's 31 prisons - worked with numerous corrections staff to achieve recruitment goals. Before the program started, MDOC staff verified release dates of potential students, implemented an application process for those who were deemed eligible, orchestrated facility transfers for prisoners accepted into the program, and created detainers to prevent random administrative transfers once courses began. In the end, MDOC received 644 applications out of 1,157 eligible prisoners across the state. Finally, a randomized selection process resulted in 150 students entering the Pathways program from 21 facilities.

\section{How Student Recruitment Impacts Reentry}

Another factor in determining student eligibility was the geographical area in which participants would return upon release. The Michigan Pathways program specifically targeted students who were expecting to return to Pontiac and Kalamazoo, where partnering community organizations could assist with student-related issues and basic reentry needs. Selecting a community to which people commonly relocate following prison will likely attract a high number of applicants to the program, strengthening enrollment numbers. Designating an uncommon post-prison destination as a return community may dissuade students from signing up while incarcerated. Many newly released prisoners rely heavily on the support of family and friends to re-establish their lives and will choose to return to the communities in which they can find those supports, as opposed to a place where they have no known resources. In the event that service providers may not be available or well-resourced in the selected return community, programs should connect with the local colleges to learn about available campus-based services that are normally covered by tuition and fees: tutoring support, food pantries, on-campus jobs, student housing, health and mental health services, to mention a few. However, as with any approach, selecting returning communities can have its advantages and disadvantages.

\section{Possible Benefits and Pitfalls of Targeting Student Reentry Communities}

One challenge that may occur when using the return community approach is that incarcerated students may feel obligated to return to an area they are not comfortable with (whether they lived there pre-incarceration or not) just so they can participate in a postsecondary program while in prison. After release, students may object to relocating to the targeted area or simply cannot relocate due to factors such as family obligations or parole requirements, thereby temporarily delaying or completely halting their studies. Another pitfall is that if eligibility for a college-in-prison program is restricted to students who are willing to commit to relocating to a limited number of return communities, the policy will inadvertently deny other potential students outside those targeted areas the opportunity to participate. College programs in corrections should make every effort to ensure that educational opportunities are inclusive, while balancing the reality of proposed reentry efforts.

Despite the possible pitfalls, there are some benefits to selecting particular areas where incarcerated students will return. One main benefit is that students in reentry who are within close proximity to one another-and the college - tend to organically form peer-support networks that promote information-sharing

\footnotetext{
${ }^{2}$ Other reasons incarcerated people cannot enroll in college level programming include facility policy that require prisoners to be free of infractions for a certain time length, being housed in segregation, or in some cases, already possessing a postsecondary degree.
} 
surrounding academics, on-campus activities and events, local reentry resources, and more. To combat costly living arrangements, students in reentry may live together in off-campus housing, sharing apartments or sometimes entire homes. Doing so provides other collateral benefits such as learning to budget personal finances and living independently, which for some students may be a new experience. Another benefit — more so for the college program or reentry organization - is that students in the same area are easier to track and reach. Students often stay in communication with one another, so if one student encounters any setbacks, such as a return to custody due to a parole violation, another student can share that with program staff so they can act quickly to remedy or mitigate the situation (e.g., withdrawing a student from courses or offering to speak on a student's behalf). Those who live far from campus or program headquarters may be more difficult to reach.

\section{Conclusion}

College-in-prison programs can take many different forms in regard to the coursework being offered, the postsecondary credentials earned upon completion, and the student selection process. Ensuring that those processes are fair and equitable is up to the academic institution and its corrections partner to determine. For example, if students are not returning to their home communities where they have social support, they may require more supportive community-based services or supervision. In Michigan, the lessons learned about recruitment for the Pathways project have informed the expansion of postsecondary education available in the DOC as additional colleges - Mott Community College and Delta College - have started teaching inside. Ideally, a thoughtful, strategic collaborative effort between the academic and correctional institution promises that incarcerated students from various backgrounds, with different offense types and returning to different communities, can have the opportunity to participate in high-quality college coursework that is challenging, rewarding, and transformative. As with any such endeavor, accomplishing even the most distant goal of the program begins with the decisions made on day one.

\section{References}

Adams, S. (1973). Higher learning behind bars. Change, 5(9), 45-50. Retrieved from http://www.jstor.org/ stable/40161892

Carson, E. A. and Anderson, E. (2016). Prisoners in 2015. Bureau of Justice Statistics. Office of Justice Programs. U.S. Department of Justice.

Delaney, R., Subramanian, R. and Patrick, F. (2016). Making the grade: Developing quality postsecondary education programs in prison. New York: Vera Institute of Justice.

Durose, M. R., Cooper, A. D., \& Snyder, H. N. (2014, April). Recidivism of Prisoners Released in 30 States in 2005: Patterns from 2005 to 2010. Retrieved from https:/www.bjs.gov/content/pub/pdf/rprts05p0510. pdf

Fine, M., Torre, M., Boudin, Bowen, I., Clark, J., Hylton, D., Martinez, M., Missy, Roberts, R. A., Smart, P., and Upegui, D. (2001). Changing Minds: The Impact of College in a Maximum-Security Prison. Retrieved from https://www.prisonpolicy.org/scans/changing_minds.pdf

Morra, L. G. (n.d.). HEHS-94-224R Pell Grants for Prison Inmates [Letter written August 5, 1994 to Senator Harris Wofford]. Retrieved from http://www.gao.gov/assets/90/84012.pdf

National Research Council. (2014). The Growth of Incarceration in the United States: Exploring Causes and Consequences. Committee on Causes and Consequences of High Rates of Incarceration. Committee on Law and Justice, Division of Behavioral and Social Sciences and Education. Washington, DC: The National Academies Press.

Rampey, B.D., Keiper, S., Mohadjer, L., Krenzke, T., Li, J., Thornton, N., and Hogan, J. (2016). Highlights from the U.S. PIAAC Survey of Incarcerated Adults: Their Skills, Work Experience, Education, and Training: Program for the International Assessment of Adult Competencies: 2014 (NCES 2016-040). U.S. Department of Education. Washington, DC: National Center for Education Statistics. Retrieved from http://nces.ed.gov/pubsearch. 
This article is supported by Grant No. 2014-DP-BX-K006, awarded by the Bureau of Justice Assistance. Points of view or opinions in this document are those of the authors and do not necessarily represent the official position or policies of the U.S. Department of Justice.

Terrell A. Blount serves as Program Associate for the Center on Sentencing and Corrections at the Vera Institute of Justice in New York.

Dr. Todd Butler serves as the Dean of the Arts \& Sciences at Jackson College in Jackson, Michigan.

Heather M. Gay is the Manager of Education for the Michigan Department of Corrections. 